\title{
O ritmo da interlíngua na produção do Português Europeu por falantes chineses
}

\author{
Chao Zhou, Marisa Cruz e Sónia Frota
}

Centro de Linguística, Universidade de Lisboa, Portugal

\begin{abstract}
:
The present research examines the rhythmic properties of European Portuguese spoken by native speakers of Mandarin Chinese. Based on the rhythm metrics and corpora used in previous studies focused on the comparison across different languages and varieties (Ramus, Nespor \& Mehler, 1999; Frota \& Vigário, 2001), we aimed at determining the rhythmic properties of the interlanguage and discussing the factors that may shape and/or constrain the grammar of the interlanguage. We analysed the rhythmic properties of sentences produced by 6 native speakers of Chinese Mandarin, with two different levels of proficiency in European Portuguese (L2) - B1 and C2. A crosscomparison analysis with the results obtained for European Portuguese (Frota \& Vigário, 2001) and for Mandarin Chinese (Lin \& Wang, 2007) was also conducted. Our results showed that the rhythm of the interlanguage evolves from L1 to L2, reflecting the proficiency level in the acquisition of European Portuguese as a L2. Additionally, we also found evidence for the influence of L1 on the grammar of the interlanguage (e.g., phonological simplifying processes such as cluster reduction in syllabic onsets or coda deletion). Although exploratory, these results contribute to further understand the intermediate linguistic status between a native and a second language, thus adding to the knowledge of the $\mathrm{L} 2$ acquisition system.
\end{abstract}

Keywords: Rhythm, Interlanguage, European Portuguese learners, Chinese Mandarin native speakers, L2 acquisition.

Palavras-chave: Ritmo, Interlíngua, Aprendentes de Português Europeu, Falantes nativos de Chinês Mandarim.

\section{Introdução}

O ritmo de uma língua é o resultado de propriedades fonéticas e fonológicas, tais como a estrutura silábica, a redução vocálica e correlatos do acento (Dasher \& Bolinger, 1982; Dauer, 1983; Frota \& Vigário, 2001). De acordo com esta perspetiva, as línguas tradicionalmente classificadas como tendo um ritmo acentual (e.g., Inglês e Holandês) apresentam uma maior variedade de estruturas silábicas do que as línguas de ritmo silábico (e.g., Espanhol e Italiano) e, ao contrário destas últimas, são caracterizadas pela presença de redução vocálica. As línguas de ritmo silábico tendem a simplificar a estrutura silábica, através de processos fonológicos como, por exemplo, a epêntese. 
Além das línguas de ritmo silábico e acentual, a análise rítmica das línguas inclui ainda o ritmo moraico, que caracteriza, por exemplo, o Japonês. Ramus, Nespor \& Mehler (1999) analisam as propriedades rítmicas de oito línguas, representando os três tipos de ritmo, com recurso a medidas que refletem diferenças na estrutura silábica das línguas, as quais são captadas por ouvintes sujeitos a testes percetivos (Ramus, Dupoux \& Mehler, 2003). De entre estas medidas, os autores destacam (i) a proporção dos intervalos vocálicos (\%V), superior nas línguas de ritmo silábico, e (ii) a variabilidade dos intervalos consonânticos $(\Delta \mathrm{C})$, superior nas línguas de ritmo acentual.

Nos estudos feitos sobre o ritmo do Português Europeu padrão (SEP), Frota \& Vigário (2000, 2001) recorreram às medidas propostas por Ramus, Nespor \& Mehler (1999), a que adicionaram medidas de normalização da velocidade discursiva ( $\Delta \% \mathrm{~V}$ e $\Delta \% \mathrm{C})$. As autoras concluem que o SEP apresenta propriedades rítmicas mistas, na medida em que se aproxima das línguas de ritmo silábico no que diz respeito à proporção vocálica $(\% \mathrm{~V})$, mas assemelha-se também às línguas de ritmo acentual, no que diz respeito à variabilidade consonântica $(\Delta \mathrm{C}$, $\Delta \% \mathrm{C}$ ). Contudo, testes percetivos mostram que as propriedades mais silábicas do Português (refletidas por \%V) são mais salientes do que as propriedades acentuais, na medida em que os participantes discriminam o Português do Holandês, língua tradicionalmente considerada de ritmo acentual (Frota, Vigário \& Martins 2002a, b).

Já quanto ao Chinês Mandarim (CM), Lin \& Wang (2007) mostram, com recurso às medidas de Ramus, Nespor \& Mehler (1999), mas também de Grabe \& Low (2002) ${ }^{1}$, que se trata de uma língua de ritmo silábico.

No que respeita às propriedades rítmicas da produção não nativa, vários trabalhos mostram uma interferência de L1 em L2. Wenk (1986), apud Ellis (1994), por exemplo, estuda o ritmo produzido por aprendentes franceses de Inglês, observando que, no início da aquisição, os aprendentes aplicam o ritmo de L1 na produção de Inglês; aprendentes de nível intermédio, apresentam um ritmo com caraterísticas de L1 e de L2; já os aprendentes proficientes exibem um ritmo muito próximo de L2. Contudo, o ritmo na produção não nativa também manifesta propriedades que não podem ser explicadas pela eventual influência de L1 ou de L2. Alouache (2016), no seu estudo sobre o ritmo de inglês produzido por aprendentes argelinos, conclui que

\footnotetext{
${ }^{1}$ Estas medidas, Pairwise Variability Indices (PVI), medem a variabilidade duracional entre intervalos vocálicos e consonânticos sucessivos. Não são, no entanto, usadas no presente trabalho, pelo que, para uma descrição detalhada das mesmas, veja-se Grabe \& Low (2002). 
os informantes têm um valor de \%V mais alto relativamente ao de L1 (Árabe) e ao de L2 (Inglês) na produção não nativa. Sendo que o Árabe e o Inglês são línguas de ritmo acentual (logo, ambas apresentam um valor de \%V baixo), esta caraterística encontrada não é predizível a partir nem de L1 nem de L2. No caso da aquisição de uma língua estrangeira por aprendentes chineses, contexto linguístico semelhante ao abordado no corrente estudo, Chen \& Chung (2008) concluem que o sistema fonológico do Chinês Mandarim (L1) tem impacto no ritmo da produção não nativa de Inglês e que os aprendentes com proficiência mais avançada apresentam, na sua produção, propriedades rítmicas de L2. Lin \& Wang (2008), depois de testarem aprendentes chineses de Inglês do Canadá, confirmam a tendência observada por Chen \& Chung (2008), na medida em que, no que diz respeito a \% , o ritmo da produção dos aprendentes chineses em causa desenvolve-se a partir de L1 para L2. No entanto, a variabilidade dos intervalos consonânticos na produção não nativa é superior à de L1 e à de L2. Lin \& Wang (2008) sugerem que a duração dos intervalos consonânticos é um aspeto difícil de adquirir por parte dos falantes nativos de Chinês Mandarim, mesmo num nível avançado de proficiência em L2.

Este trabalho tem como objetivo examinar o ritmo da interlíngua na produção do Português Europeu por falantes de Chinês Mandarim, tópico que, tanto quanto é do nosso conhecimento, ainda não foi estudado. Pretende-se, assim, contribuir para a caracterização das propriedades rítmicas da interlíngua e discutir o impacto de L1 e L2 nessas propriedades.

$\mathrm{Na}$ secção seguinte, apresenta-se uma breve contextualização sobre a noção da interlíngua. De seguida, na secção 3, definem-se os procedimentos metodológicos adotados. Os resultados são descritos e discutidos na secção 4, seguida da conclusão e da discussão de linhas de trabalho futuro, na secção 5 .

\section{Interlíngua: breve enquadramento}

$\mathrm{Na}$ literatura em aquisição da língua materna, muitos autores defendem que as crianças que estão a adquirir a língua materna (L1) têm uma gramática sistemática e que os erros produzidos não são apenas uma imitação falhada das produções dos adultos (McNeill, 1966; Fikkert 1994; Freitas 1997). Aplicada à aquisição de uma língua segunda (L2), esta ideia da gramática independente tornou-se a hipótese da interlíngua (Selinker, 1972): o sistema linguístico de aprendentes não é uma versão defetiva da língua-alvo, mas um estádio intermédio em desenvolvimento com propriedades particulares. A gramática da interlíngua é um sistema 
mental desenvolvido por um aprendente de L2, e tem sido um dos desenvolvimentos principais na teoria de aquisição de uma língua segunda. A ideia principal subjacente à noção da interlíngua é a de que os aprendentes de L2 constroem a sua própria versão de L2. Sob este ponto de vista, a aquisição de L2 implica a construção de uma gramática própria, a interlíngua.

Embora a aquisição da gramática da interlíngua possa ter uma base nas estruturas transferidas a partir de L1, e no input de L2, vários trabalhos evidenciam que alguns erros na produção não nativa não podem ser atribuídos nem a L1 nem a L2. Altenberg \& Vago (1983), por exemplo, verificam que os informantes de L1 Húngaro e L2 Inglês desvozeam sistematicamente as obstruintes em posição final da palavra, o que é interessante porque nem o Húngaro nem o Inglês têm a regra de desvozeamento final. Ambas as línguas têm o contraste de vozeamento em posição final de palavra. Por isso, a regra de desvozeamento final observada nas produções dos informantes é independente de L1 e de L2. No estudo de Eckman (1981), os falantes de L1 Espanhol e de Inglês L2 também parecem formular uma regra de desvozeamento final na gramática da interlíngua, e que também é independente de L1 e L2. A hipótese da interlíngua oferece-nos uma possibilidade para dar conta de dados empíricos como estes.

A questão central do presente trabalho reside na tentativa de caracterização do ritmo da interlíngua. Será o ritmo na produção do Português Europeu por parte de aprendentes chineses apenas o resultado de uma fase intermédia no desenvolvimento de L1 para L2, à semelhança do observado por Wenk (1986), apud Ellis (1994), e Chen \& Chung (2008)? Ou apresentar-seão padrões não preditos quer por L1, quer por L2, tal como apontado por Alouache (2016)? Tentando responder às questões acima, procurámos observar:

1. Quais as características do ritmo na produção do Português Europeu por aprendentes chineses;

2. Quais os fatores que legitimam o ritmo da interlíngua.

De modo a responder às questões levantadas, foram analisadas as propriedades rítmicas da produção do Português Europeu (L2) por aprendentes chineses. Na secção abaixo, são descritos os procedimentos metodológicos inerentes a este estudo. 


\section{Metodologia}

\subsection{Participantes}

Foram selecionados seis falantes nativos de Chinês Mandarim (CM), todos do sexo feminino, com idades compreendidas entre os 20 e os 24 anos. De entre as seis participantes, três estudam Português Europeu (PE) há um ano e detêm o nível de proficiência B1. As restantes estudam Português Europeu há cinco anos e detêm o nível de proficiência C2. Nenhuma das participantes apresenta qualquer perturbação auditiva, discursiva ou de escrita/leitura.

\subsection{Materiais}

Porque o intuito é estabelecer uma comparação direta entre as propriedades rítmicas da interlíngua e as de L2 (PE), foram selecionadas as cinco frases adaptadas para o PE por Frota \& Vigário (2000, 2001), a partir dos materiais usados por Ramus, Nespor \& Mehler (1999) para a análise comparativa de outras línguas. Abaixo, listam-se essas mesmas frases, cuja extensão silábica varia entre 15 e 19 sílabas.

(1) Um quadro de grande valor foi leiloado ontem.

(2) O novo presidente será eleito em Outubro.

(3) Os artistas foram sempre atraídos pelas cidades.

(4) A descida das taxas de juro foi muito elogiada.

(5) A inflação subiu cerca de cinco pontos no ano passado.

\subsection{Recolha e tratamento dos dados}

A recolha de dados foi feita no país de origem das participantes (China). As participantes foram instruídas a ler silenciosamente cada uma das frases antes da produção das mesmas em voz alta, por forma a evitar a eventual ocorrência de disfluências causadas pelo desconhecimento das frases. No total, foram obtidos 30 enunciados, os quais foram analisados, seguindo os critérios detalhados abaixo.

Após a gravação, procedeu-se à segmentação dos dados a fim de ter os valores relevantes para a análise do ritmo. Todos os ficheiros de áudio gravados foram anotados no programa Praat (Boersma \& Weenink, 2016), onde se criaram duas fiadas alinhadas com o espectrograma, conforme ilustrado na Figura 1: uma para a transcrição ortográfica palavra a 
palavra ('Ortografia'), e outra para a segmentação dos intervalos vocálicos e consonânticos, com base nas pistas espectrográficas e auditivas ('Intervalo').

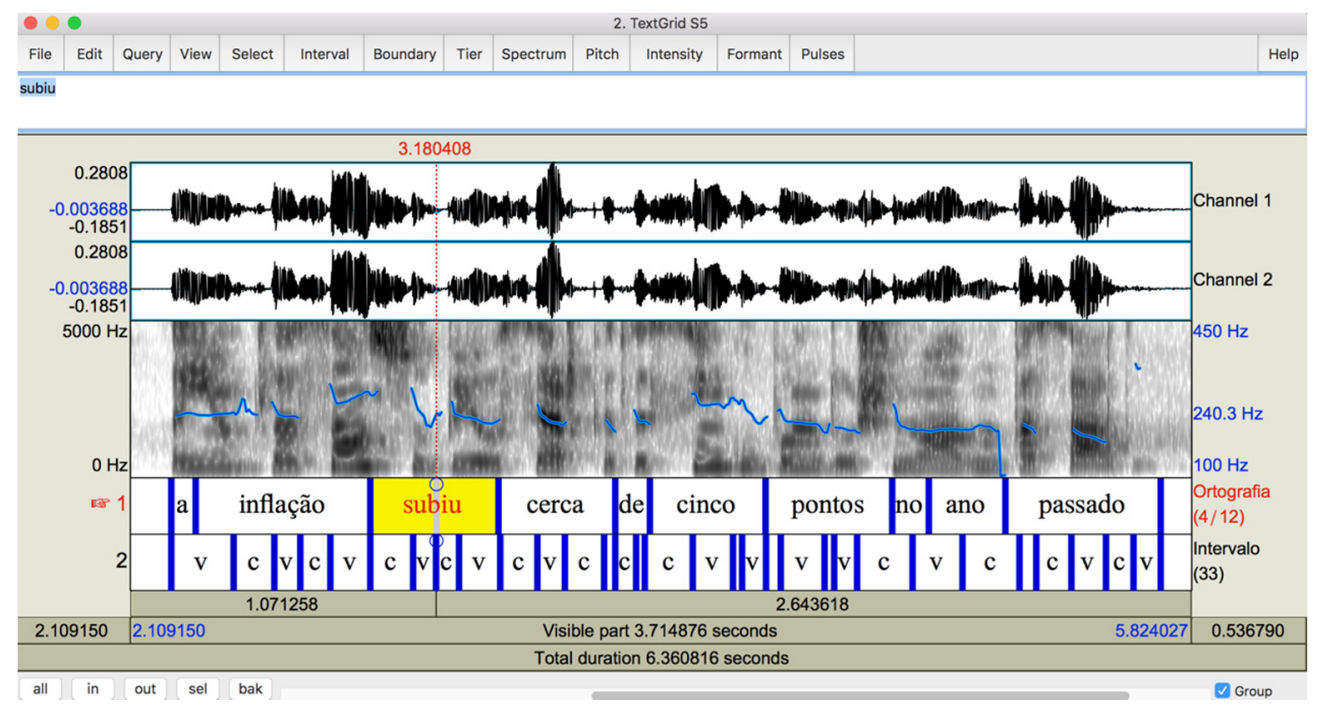

Figura 1: Segmentação dos intervalos vocálicos e consonânticos da frase $A$ inflação subiu cerca de cinco pontos no ano passado, produzida pela informante Sílvia (proficiência C2).

Para a segmentação dos intervalos vocálicos e consonânticos, seguiram-se os critérios de Frota \& Vigário (2001) e os de Turk et al. (2006), nomeadamente:

(i) O intervalo entre o início e o fim de uma vogal (ou sequência de vogais) é designado como intervalo vocálico e etiquetado com ' $\mathrm{v}$ ';

(ii) O intervalo entre o início e o fim de uma consoante (ou sequência de consoantes) é designado como intervalo consonântico e etiquetado com 'c';

(iii) O VOT (Voice Onset Time) das consoantes oclusivas é agrupado no intervalo consonântico;

(iv) As semivogais pós-vocálicas (ditongos decrescentes) são agrupadas no intervalo vocálico;

(v) As semivogais pré-vocálicas (ditongos crescentes) são agrupadas no intervalo consonântico;

(vi) Pausas e/ou intervalos de silêncio que não têm significado linguístico (esperados, por exemplo, na produção dos falantes com a proficiência mais baixa (B1)) são etiquetados com ' $b$ '. 
Para garantir a qualidade da segmentação dos intervalos vocálicos e consonânticos, os dados foram sistematicamente revistos pelo segundo autor. Os poucos casos não consensuais ou que suscitaram dúvida (1\%) foram revistos pelo terceiro autor.

Depois da segmentação, os ficheiros anotados gerados no Praat (Textgrid) foram introduzidos no programa Correlatore (Mairano, 2009) para extrair as medidas acústicas relevantes de forma automática. Os intervalos etiquetados com ' $b$ ' foram automaticamente desconsiderados no cálculo feito pelo Correlatore.

Por fim, importa referir que as medidas acústicas utilizadas neste trabalho foram duas das propostas por Ramus, Nespor \& Mehler (1999) - a proporção dos intervalos vocálicos (\%V) e a variabilidade dos intervalos consonânticos $(\Delta \mathrm{C})$-, pelo facto de, conforme já referido na secção 1, estas serem as medidas que melhor se correlacionam com a organização das línguas nas três classes rítmicas, constituindo ainda o reflexo das respetivas propriedades fonéticofonológicas, que influenciam a perceção do ritmo. Adicionalmente a estas duas medidas, considerou-se ainda a medida normalizada proposta por Frota \& Vigário (2001) para o cálculo da variabilidade dos intervalos consonânticos $(\Delta \% \mathrm{C})$, no que diz respeito à velocidade de fala. De acordo com as autoras, a variabilidade da duração dos intervalos consonânticos pode ser influenciada pela velocidade discursiva. Por conseguinte, para contornar o efeito da velocidade de fala, o valor da variabilidade da duração consonântica deve ser dividido pela duração total da unidade de produção em análise, neste caso, o sintagma entoacional (IP). Naturalmente, espera-se que os falantes não nativos tenham uma velocidade de fala inferior à dos nativos, refletindo também o nível de proficiência, isto é, quanto menos proficientes forem os falantes em L2, mais lenta será a sua velocidade de fala. Assim sendo, e por forma a evitar a influência da velocidade de fala na análise acústica dos dados, o recurso à medida normalizada proposta por Frota \& Vigário (2001) é crucial. Os valores de $\% \mathrm{~V}$ e de $\Delta \% \mathrm{C}$ foram calculados separadamente para os grupos de proficiência B1 e C2.

\section{Resultados e Discussão}

Nesta secção, apresentam-se os resultados da análise rítmica dos enunciados produzidos pelos falantes chineses aprendentes de PE comparativamente aos resultados previamente obtidos para o PE e para o CM por Frota \& Vigário (2000, 2001) e Lin \& Wang (2007), respetivamente. 
Conforme se pode observar na Tabela 1, os falantes chineses aprendentes de Português Europeu podem ser divididos em dois grupos (cujas medidas estão assinaladas a vermelho e a azul), refletindo o nível de proficiência que detêm em L2 (PE): os falantes com a proficiência mais elevada (C2) têm valores mais próximos de L2 (vermelho); os falantes com a proficiência mais baixa (B1) têm valores mais próximos de L1(azul).

Assim, considerando os valores da proporção de intervalos vocálicos $(\% \mathrm{~V})$, depreendese que os falantes com a proficiência mais elevada (C2) tenham já adquirido o processo fonológico muito produtivo em $\mathrm{PE}$, a redução vocálica, bem como processos fonéticofonológicos de elisão vocálica (Frota \& Vigário, 2001; Vigário, 2003) e que os apliquem gradualmente na produção, não tendo, no entanto, alcançado ainda o valor de \%V de L1 $(46,6)$. Contudo, no caso dos falantes com o nível de proficiência B1, estes processos ainda não estarão completamente disponíveis na gramática da interlíngua, na medida em que os valores de \%V estão claramente mais afastados dos de \%V de L2 e mais próximos dos valores de \%V de L1 $(56,2)$.

\begin{tabular}{|l|l|l|}
\hline & $\% \mathrm{~V}$ & $\Delta \% \mathrm{C}$ \\
\hline PE & 46.6 & 2.6 \\
\hline Gloria (C2) & 49.9 & 5.4 \\
\hline Carolina (C2) & 49.1 & 4.0 \\
\hline Sílvia (C2) & 50.7 & 4.1 \\
\hline Yang (B1) & 58.1 & 5.9 \\
\hline Amélia (B1) & 56.5 & 7.0 \\
\hline Genoveva (B1) & 57.7 & 6.3 \\
\hline CM & 56.2 & -- \\
\hline
\end{tabular}

Tabela 1. Sumário dos resultados obtidos para as duas medidas acústicas consideradas. Os dados do PE provêm de Frota \& Vigário (2001) e os do Chinês Mandarim provêm de Lin \& Wang (2007). 
Na dimensão da variabilidade da duração consonântica, e embora não tenhamos o valor de $\Delta \%$ C para o CM, uma vez que Lin \& Wang (2007) não tiveram em conta o cálculo desta medida normalizada para a velocidade de fala, assume-se que, conforme a natureza rítmica silábica do $\mathrm{CM}$, o valor de $\Delta \% \mathrm{C}$ seja mais baixo do que o do $\mathrm{PE}(2,6)$. Se no caso de $\% \mathrm{~V}$ se observa um claro domínio, por parte dos falantes mais proficientes de PE como L2, da proporção vocálica característica da língua, no caso da variabilidade da duração consonântica os resultados são menos claros, na medida em que os valores de $\Delta \% \mathrm{C}$ estão muito afastados dos de CM (L1) e dos de PE (L2). Concretamente, observa-se ainda que os falantes com um nível de proficiência mais baixo (B1) apresentam valores de variabilidade consonântica ainda mais elevados do que os de proficiência mais elevada (C2), o que mostra que os falantes chineses não conseguem controlar esta dimensão da língua como controlam a proporção vocálica, apontando para dois estádios diferentes para a aquisição de cada uma destas duas dimensões que contribuem para a caracterização rítmica de L2.

Uma outra evidência sobre a proeminência do espaço vocálico em detrimento do consonântico foi registada em Vigário, Frota \& Freitas (2003). As autoras, na linha de Frota \& Vigário (2001), também destacam a saliência percetiva de \%V relativamente à de $\Delta \mathrm{C}$. Deste modo, parece ficar clara a razão pela qual os falantes chineses adquirem a duração vocálica via input mais cedo do que a duração consonântica.

Contudo, além do impacto da língua de input (L2) na interlíngua, os dados também apresentam pistas para a transferência de L1, visíveis nos dois níveis de proficiência de L2, por exemplo, na simplificação do ataque ramificado (e.g., <pesidente > por < presidente>, Yang, B1; <ataídos> por <atraídos>, Glória, C2) e na supressão da coda (e.g., <atistas> por <artistas>, Yang, B1; $<$ decida $>$ por $<$ descida $>$, Genoveva, B1; $<$ taxa $>$ por $<$ taxas $>$, Glória, C2). Estes processos, ainda que não operem sistematicamente, resultam no aumento de \%V e parecem decorrer da transferência de L1. De facto, o Chinês Mandarim (Duanmu, 2007; Lin, 2007) tem um sistema consonântico e uma estrutura silábica mais simples do que o PE (Mateus \& d'Andrade, 2000). No CM, não existem grupos consonânticos, estrutura possível no PE, e as regras fonotáticas diferentes entre as duas línguas permitem ainda a emergência de segmentos diferenciados em posições silábicas ocupadas por consoantes. No Português Europeu, o ataque ramificado pode ser uma combinação de uma consoante oclusiva e uma consoante líquida ou uma consoante fricativa e uma consoante líquida. Porém, na gramática de CM, quanto ao ataque, apenas uma posição está disponível no esqueleto da estrutura silábica, o que 
desencadeia a dificuldade, para os falantes chineses, em associar dois segmentos a uma só posição no esqueleto da estrutura silábica, que é o que está disponível na gramática de L1. Como consequência, em alguns casos, os falantes optam pela simplificação do ataque ramificado em L2. Já quanto à posição de coda, em Português Europeu, ela pode ser preenchida por /1/, /r/ e /s/ (Mateus \& d'Andrade, 2000); porém, no Mandarim, apenas /ð/, /n/ e /n/ são permitidos (Duanmu, 2007). O recurso ao apagamento da coda por parte dos falantes chineses revela o não domínio das regras fonotáticas e/ou do inventário sonoro de L2, já que, por vezes, transferem alguns dos sons de L1 para L2 (e.g., val[ə] por val[or], Carolina, C2).

Em suma, e na linha de Wenk (1986) e Chen \& Chung (2008), os resultados aqui observados mostram que o ritmo da interlíngua se desenvolve de L1 para L2, refletindo, naturalmente, os níveis de proficiência: quanto menor a proficiência em L2, maior a interferência de L1; quanto mais elevado é o nível de proficiência em L2, maior é a proximidade em relação ao ritmo de L2.

\section{Conclusão}

No presente estudo, pretendeu-se examinar a natureza do ritmo do Português Europeu (PE) como língua segunda, produzido por falantes nativos de Chinês Mandarim (CM). Recorrendo às medidas propostas por Ramus, Nespor \& Mehler (1999) e Frota \& Vigário (2000, 2001), analisou-se o ritmo da produção não nativa e discutiram-se as eventuais influências de L1 (CM), classificada como língua de ritmo silábico (Lin \& Wang, 2007) e de L2 (PE), considerado por Frota \& Vigário (2000, 2001) como uma língua com propriedades rítmicas mistas, embora com clara preponderância percetiva das propriedades silábicas (Frota, Vigário \& Martins, 2002a, b).

Foram analisados dados da produção de seis falantes nativos de Mandarim em dois níveis de proficiência (B1 e C2). Os resultados obtidos permitiram observar que, com o aumento da proficiência, o ritmo da interlíngua fica mais próximo do ritmo do alvo. Constatou-se ainda que os falantes nativos de Mandarim têm mais dificuldade em adquirir a duração dos intervalos consonânticos do que a dos intervalos vocálicos, o que também foi observado na aquisição do ritmo do Inglês (L2) por parte de falantes nativos do Mandarim (Lin \& Wang, 2008). Adicionalmente, processos como a simplificação do ataque ramificado, a supressão da coda e a preservação de sons do inventário sonoro do Chinês Mandarim na interlíngua revelam uma 
clara influência da gramática de L1, reforçando a hipótese de que a interferência de L1 é determinante para o ritmo da interlíngua (Wenk, 1986; Chen \& Chung, 2008; Lin \& Wang, 2008; entre outros). O ritmo da interlíngua não apresenta, assim, características não explicáveis por L1 e/ou L2.

Constituem limitações do presente estudo o tamanho da amostra e a ausência de um estudo sistemático dos processos produzidos pelos falantes de CM em PE L2, pois seria necessário alargar a dimensão da amostra para cada nível de proficiência e analisar, de forma sistemática e detalhada, os erros produzidos pelos aprendentes de PE como L2. Tais objetivos serão abordados em trabalho futuro.

\section{Agradecimentos}

Agradecemos a todas as informantes envolvidas na tarefa de produção pela disponibilidade e colaboração, bem como aos comentadores anónimos pelas sugestões apresentadas.

\section{Referências}

Alouache, Amel (2016) The rhythmic classification of Algerian EFL undergraduates' interlanguage: A comparison of two approaches. Al Athar 15(26), 79-88.

Altenberg, Evelyn P. \& Robert M. Vago (1983) Theoretical implications of an error analysis of second language phonology production. Language Learning 33(4), 427-447.

Boersma, Paul \& David Weenink (2016) Praat-doing phonetics by computer. Version 6.0.15 [www.praat.org].

Chen, Hsueh-chu \& Raung-fu Chung (2008) Interlanguage analysis of phonetic timing patterns by Taiwanese learners. Concentric: Studies in Linguistics 34(1), 79-108.

Dasher, Richard \& Dwight Bolinger (1982) On pre-accentual lengthening. Journal of the International Phonetic Association 12, 58-69.

Dauer, Rebecca (1983) Stress-timing and syllable-timing reanalyzed. Journal of Phonetics 11, 51-62.

Duanmu, San (2007) The Phonology of Standard Chinese (2nd ed.). Oxford: Oxford University Press. 
Eckman, Fred R. (1981) On the naturalness of interlanguage phonological rules. Language Learning 31(1), 195-216.

Ellis, Rod (1994) The study of second language acquisition. Oxford: Oxford University Press. Fikkert, Paula (1994) On the acquisition of prosodic structure. Doctoral Dissertation 6, Holland Institute of Generative Linguistics, Leiden University, Holland Academic Graphics.

Freitas, Maria João (1997) Aquisição da estrutura silábica do Português Europeu. Doctoral dissertation, University of Lisbon.

Frota, Sónia \& Marina Vigário (2000) Aspectos de prosódia comparada: ritmo e entoação no PE e no PB. In Rui V. Castro \& Pilar Barbosa (eds.) Actas do XV Encontro Nacional da Associação Portuguesa de Linguística, vol.1. Coimbra: Associação Portuguesa de Linguística, pp. 533-555.

Frota, Sónia \& Marina Vigário (2001) On the correlates of rhythmic distinctions: the European/Brazilian Portuguese case. Probus 13, 247-273.

Frota, Sónia, Marina Vigário \& Fernando Martins (2002a) Language Discrimination and Rhythm Classes: Evidence from Portuguese. In Proceedings of Speech Prosody 2002, Aix en Provence, pp. 315-318.

Frota, Sónia, Marina Vigário \& Fernando Martins (2002b) Discriminação entre línguas: evidência para classes rítmicas. In Actas do XVII Encontro da APL. Lisboa: Associação Portuguesa de Linguística/Colibri, pp. 189-199.

Grabe, Esther \& Ee Ling Low (2002) Durational variability in speech and the rhythm class hypothesis. In Carlos Gussenhoven \& Natasha Warner (eds.) Laboratory Phonology 7. Berlin: Mouton de Gruyter, pp. 515-546.

Lin, Hua \& Qian Wang (2007) 林华、王倩。Mandarin rhythm: An acoustic study. 普通话节 律的声学研究。Journal of Chinese Linguistics and Computing 17(3), 127-140.

Lin, Hua \& Qian Wang (2008) Interlanguage rhythm in the English production of Mandarin speakers. In Proceedings of the 8th Phonetic Conference of China and the International Symposium on Phonetic Frontiers, Beijing, April 18-20.

Lin, Yen-Hwei (2007) The Sounds of Chinese. Cambridge: Cambridge University Press.

Mairano, Paolo (2009) Correlatore 2.1.

[http://www.lfsag.unito.it/correlatore/download_en.html]. 
Mateus, Maria Helena Mira \& Ernesto d'Andrade (2000) The Phonology of Portuguese. Oxford: University Press.

McNeill, David (1966) Developmental psycholinguistics. In Frank Smith \& George A. Miller (eds.) The genesis of language, A psycholinguistic approach. Cambridge, Mass: MIT Press, pp. $15-84$.

Ramus, Franck, Marina Nespor \& Jacques Mehler (1999) Correlates of linguistic rhythm in the speech signal. Cognition 73(3), 265-292.

Ramus, Franck, Emmanuel Dupoux \& Jacques Mehler (2003) The psychological reality of rhythm classes: Perceptual studies. Paper presented at the 15th International Congress of Phonetic Sciences, Barcelona, pp. 337-342.

Selinker, Larry (1972) Interlanguage. IRAL-International Review of Applied Linguistics in Language Teaching 10 (1-4), 209-232.

Turk, Alice, Satsuki Nakai \& Mariko Sugahara (2006) Acoustic segment durations in prosodic research: a practical guide. In Stefan Sudhoff, Denisa Lenertova, Roland Meyer, Sandra Pappert, Petra Augurzky, Ina Mleinek, Nicole Richter \& Johannes Schliesser (eds.) Methods in Empirical Prosody Research. Berlin: Mouton de Gruyter, pp. 1-28.

Vigário, Marina (2003) The Prosodic Word in European Portuguese. (Interface Explorations Series, 6). Berlin/ New York: Mouton de Gruyter.

Vigário, Marina, Sónia Frota \& Maria João Freitas (2003) From Signal to Grammar: Rhythm and the Acquisition of Syllable Structure. In Barbara Beachley, Amanda Brown \& Frances Conlin (eds.) Proceedings of the 27th Boston University Conference on Language Development. Dommerville, Massachusetts: Cascadilla Press, pp. 809-821. 